\title{
Availability of Medications for the Treatment of Alcohol and Opioid Use Disorder in the USA
}

\author{
Amanda J. Abraham ${ }^{1}$ (D) Christina M. Andrews ${ }^{2} \cdot$ Samantha J. Harris ${ }^{1} \cdot$ Peter D. Friedmann ${ }^{3}$ \\ Published online: 6 January 2020 \\ (C) The American Society for Experimental NeuroTherapeutics, Inc. 2020
}

\begin{abstract}
Despite high mortality rates due to opioid overdose and excessive alcohol consumption, medications for the treatment of alcohol and opioid use disorder have not been widely used in the USA. This paper provides an overview of the literature on the availability of alcohol and opioid used disorder medications in the specialty substance use disorder treatment system, other treatment settings and systems, and among providers with a federal waiver to prescribe buprenorphine. We also present the most current data on the availability of alcohol and opioid use disorder medications in the USA. These estimates show steady growth in availability of opioid use disorder medications over the past decade and a decline in availability of alcohol use disorder medications. However, overall use of medications in the USA remains low. In 2017, only $16.3 \%$ of specialty treatment programs offered any single medication for alcohol use disorder treatment and 35.5\% offered any single medication for opioid use disorder treatment. Availability of buprenorphine-waivered providers has increased significantly since 2002 . However, geographic disparities in access to buprenorphine remain. Some of the most promising strategies to increase availability of alcohol and opioid use disorder medications include the following: incorporating substance use disorder training in healthcare education programs, educating the substance use disorder workforce about the benefits of medication treatment, reducing stigma surrounding the use of medications, implementing medications in primary care settings, implementing integrated care models, revising regulations on methadone and buprenorphine, improving health insurance coverage of medications, and developing novel medications for the treatment of substance use disorder.
\end{abstract}

Key Words Alcohol use disorder $\cdot$ opioid use disorder $\cdot$ medication treatment $\cdot$ specialty treatment $\cdot$ buprenorphine-waivered providers.

Amanda J. Abraham

aabraham@uga.edu

Christina M. Andrews

candrews@mailbox.sc.edu

Samantha J. Harris

samantha.harris27@uga.edu

Peter D. Friedmann

peter.friedmannmd@baystatehealth.org

1 School of Public and International Affairs, University of Georgia, 280F Baldwin Hall, 355 S. Jackson Street, Athens, GA 30602, USA

2 College of Social Work, University of South Carolina, 1512 Pendleton St., Room 309, Columbia, SC 29208, USA

3 University of Massachusetts Medical School Baystate, 280 Chestnut St., Springfield, MA 01199, USA

\section{Introduction}

Approximately one in 14 Americans, or $7.2 \%$ of those aged 12 and older, have a substance use disorder [1]. Alcohol use disorder accounts for a majority of substance use disorder cases in the USA, with 14.5 million or $5.3 \%$ of Americans aged 12 or older meeting diagnostic criteria for an alcohol use disorder in 2017. Approximately 2.1 million Americans met diagnostic criteria for an opioid use disorder in 2017 [1]. As the nation's opioid epidemic continues to escalate, it is likely that this number will continue to rise in the years ahead.

The social and economic costs of untreated alcohol and drug use in the USA are substantial. In 2013, the estimated costs of prescription opioid overdose, abuse, and misuse were $\$ 78.5$ billion [2]. Drug overdose deaths, estimated at 70,237 in 2017, are now outpacing deaths at the height of the HIV/AIDS epidemic [3]. Opioid overdose deaths account for the majority of drug overdose mortalities in the nation, representing 47,600 of all such deaths in 2017. Costs associated with excessive 
drinking are also high — estimated at $\$ 249$ billion in 2010. The median cost of excessive drinking per state was $\$ 3.5$ billion in the same year [4]. Approximately 88,000 Americans per year die as a result of excessive alcohol consumption - accounting for approximately one in 10 deaths among working-age adults [5].

A large body of research demonstrates the effectiveness of medication for treatment of opioid use disorder [6-13]. Used in conjunction with psychosocial therapy, medications are considered the gold standard in care for the treatment of opioid use disorder [7-10]. Opioid use disorder treatment medications are associated with reductions in opioid use, withdrawal, craving, and treatment dropout [7, 8, 10, 12-14]. A recent report by the National Academies of Sciences, Engineering, and Medicine concluded that "a lack of availability or utilization of behavioral interventions is not a sufficient justification to withhold medications to treat opioid use disorder" [15]. This statement reflects mounting support for the use of medications in the absence of psychosocial therapy.

Use of alcohol use disorder medications is associated with reductions in the risk of heavy drinking, number of drinking days, number of heavy drinking days, the amount of alcohol consumed per drinking day, craving, as well as increases in the rate of abstinence [16-31]. The evidence base is stronger for naltrexone and acamprosate, compared to disulfiram, which showed mixed results in clinical trials [32-35].

Despite high rates of substance use disorder in the USA, in any given year, only about $10 \%$ of Americans with substance use disorder receive any type of substance use disorder treatment and only a small fraction receive an FDA-approved medication as part of their treatment [1,36, 37]. A majority of Americans seek treatment in the specialty substance use disorder treatment system, which is comprised of outpatient, residential, and hospital inpatient treatment programs that specialize in the treatment of the disorder. Nonspecialty treatment settings include emergency rooms, offices of private physicians, prisons or jails, or self-help groups [1].

Over the past 15 years, there have been significant efforts to increase the availability of medications to treat alcohol and opioid use disorder. In the USA, the National Institute on Drug Abuse and the National Institute on Alcoholism and Alcohol Abuse have invested significant resources to promoting the availability of medications in specialty and nonspecialty treatment settings, particularly primary care [38-41]. Despite these efforts, medications for treatment of substance use disorder have not been widely available in any treatment setting in the USA.

In this article, we provide an overview of the literature on the availability of alcohol and opioid use disorder medications in the specialty substance use disorder treatment system, other relevant treatment settings and systems, and the availability of buprenorphine-waivered providers in the USA. To supplement this literature, we also present the most current data from the specialty substance use disorder treatment system and Drug Enforcement Agency (DEA) list of buprenorphinewaivered providers. Specifically, we examine changes in the availability of alcohol and opioid use disorder medications in the specialty substance use disorder treatment system from 2014 to 2017 [42], as well as changes in the number of buprenorphine-waivered providers from 2017 to 2019. We then discuss the implications of these findings and conclude with the most promising avenues to improve the availability of medications for alcohol and opioid use disorder treatment in the USA.

\section{FDA-Approved Medications for the Treatment of Alcohol and Opioid Use Disorder}

\section{Alcohol Use Disorder Medications}

There are currently four medications approved by the Food and Drug Administration (FDA) for the treatment of alcohol use disorder: disulfiram, acamprosate, oral naltrexone, and injectable naltrexone. Disulfiram, FDA-approved for alcohol treatment in 1951, is an alcohol-aversive medication that causes a severe physical reaction (e.g., increased pulse and respiration, tachycardia, facial flushing, nausea, vomiting, hypotension) when mixed with alcohol $[32-35,43]$. Acamprosate, FDA-approved in 2004, is a glutamate antagonist that is thought to modulate glutamatergic neurotransmission, thus reducing the symptoms of post-acute withdrawal $[18,23,43-47]$. Acamprosate is indicated for maintenance of abstinence from alcohol in patients with alcohol dependence who are abstinent [43]. Oral and injectable naltrexone are high-affinity opioid receptor antagonists that block the opiate receptors in the brain and inhibit the effects of opioids. Naltrexone is thought to block endogenous opioids triggered by alcohol and has been found to reduce craving and help prevent relapse to heaving drinking [16, 23, 48, 49]. The oral formulation was FDA-approved for alcohol use disorder treatment in 1994 and the extended-release injectable formulation was FDA-approved in 2006. Oral naltrexone must be taken daily and is administrated in tablet form; the extended-release formulation is administered once monthly via an intramuscular injection.

Alcohol use disorder medications are not scheduled narcotics and can be prescribed by any physician or healthcare professional with prescribing privileges. Naltrexone is the most widely used medication for the treatment of alcohol use disorder. Because the oral formulation of naltrexone must be taken daily, patient compliance has been a barrier to its effectiveness [50-53]. Although the injectable formulation overcomes this barrier, it can be prohibitively expensive (retail cost of $\$ 1100$ to $\$ 1200$ per monthly dose) and is more difficult to administer than oral medications [53, 54]. A clinical trial 
comparing oral naltrexone to extended-release injectable naltrexone for opioid use disorder found twice the rate of treatment retention at 6 months for injectable naltrexone [55]. A head-to-head trial is currently underway comparing the two medications for alcohol use disorder treatment in primary care settings. Study outcomes will include the probability of a "Good Clinical Outcome" as well as an estimate of the incremental cost-effectiveness of each medication [53].

\section{Opioid Use Disorder Medications}

Four medications are currently FDA-approved for the treatment of opioid use disorder: oral naltrexone, extended-release injectable naltrexone, methadone, and buprenorphine. As described above, oral and injectable naltrexone are also FDAapproved for the treatment of alcohol use disorder. Oral naltrexone was FDA-approved for opioid treatment in 1984. While the current FDA label indicates oral naltrexone for the blockade of the effect of exogenously administered opioids, the oral formulaton has not demonstrated efficacy in clinical trials. The extended-release injectable formulation was FDAapproved for the prevention of relapse to opioid dependence in 2010. Patients must be opioid free for 7 to 10 days before beginning naltrexone treatment.

Methadone is a full opioid agonist and has been used in the treatment of opioid use disorder in the USA since the 1960s. It is a schedule II narcotic and is highly regulated by the U.S. government. Methadone can only be dispensed in licensed opioid treatment programs (OTPs).

Buprenorphine, a partial opioid agonist, is a schedule III narcotic and can only be prescribed by physicians holding a Drug Addiction Treatment Act (DATA) 2000 waiver [56]. In order to prescribe scheduled narcotics in the USA, providers must register with the DEA. To prescribe buprenorphine, providers must take the additional step of completing an 8-h course to obtain a DATA 2000 waiver from the DEA. The ability to obtain a buprenorphine waiver was extended to physician assistants (PAs) and nurse practitioners (NPs) (in some states) in the year 2017. Unlike methadone, buprenorphine can be prescribed in office-based settings (outside of OTPs) by any provider holding a waiver. There are, however, limits on the number of patients a waivered provider can prescribe to at one time. In the first year of holding a waiver, providers can prescribe buprenorphine to up to 30 patients at one time. After one year, providers can apply to prescribe buprenorphine to up to 100 patients at one time, and after another year, providers can apply to prescribe buprenorphine to up to 275 patients at one time. The patient limit was raised to 100 in 2016 and 275 in 2017.

Methadone and buprenorphine are the most widely used medications for the treatment of opioid use disorder in the USA. Compared with naltrexone, the evidence base is stronger for the use of methadone and buprenorphine in the treatment of opioid use disorder $[6,57,58]$. Another potential disadvantage of naltrexone is that patients must be opioid free for 7 to 10 days prior to treatment initiation, which is not the case for methadone or buprenorphine $[52,59]$.

\section{Availability of Medications in Specialty Substance Use Disorder Treatment Settings}

A large body of research has investigated the availability of medications to treat alcohol and opioid use disorder in the specialty substance use disorder treatment system [36, 60-83]. The specialty substance use disorder treatment system is comprised of approximately 13,400 programs, including 1293 OTPs [84]. The majority of specialty treatment programs offer outpatient treatment (83.3\%). Approximately $22.8 \%$ offer residential treatment, $4.6 \%$ offer hospital inpatient treatment, and $18.6 \%$ offer some form of detoxification.

We summarize this literature by first describing early studies of medication availability and then providing the most current data on medication availability from the National Drug Abuse Treatment System Survey (NDATSS), a nationally representative, longitudinal study of specialty substance use disorder treatment programs in the USA. We present two measures of medication availability that are used in this literature. The first and most commonly used measure is the percentage of specialty substance use disorder treatment programs that offer an alcohol or opioid use disorder medication $[42,61,63-66,69,83,85,86]$. The second measure, which indicates the extent of medication use, is the percentage of patients with an alcohol or opioid use disorder who receive an FDA-approved medication [36, 70, 83].

\section{Availability of Alcohol Use Disorder Medications}

Early studies of oral naltrexone and disulfiram availability in the specialty treatment system showed relatively high rates of availability, with almost half of privately funded substance use disorder treatment programs offering these medications for alcohol treatment $[70,82]$. However, these rates declined substantially from 1995 to 2008 [36, 66, 83], with less than one third of specialty treatment programs offering any single medication for the treatment of alcohol use disorder in 2007 2008.

In terms of the percentage of patients receiving alcohol medications, early studies of privately funded specialty treatment programs found that less than $15 \%$ of alcohol patients received oral naltrexone $(13.2 \%)$ or disulfiram $(11.2 \%)$ [70, 83]. Data from 2007 to 2008 showed little change in the percentage of patients receiving either medication. However, a higher percentage $(17.5 \%)$ of patients with alcohol use disorder in privately funded treatment programs received acamprosate [36]. 


\section{NDATSS: 2014-2017}

The most current data from NDATSS shows that availability of alcohol use disorder medications has remained low in the post-Affordable Care Act era (see Table 1). With the exception of injectable naltrexone, the percentage of specialty substance use disorder treatment programs offering medications for alcohol use disorder treatment did not significantly change from
2014 to 2017 (see Table 1). About $8.7 \%$ of treatment programs offered acamprosate, $10.5 \%$ offered disulfiram, and $16.3 \%$ offered oral naltrexone in 2017 . The percentage of programs offering injectable naltrexone increased from $7.5 \%$ of programs in 2014 to $11.1 \%$ in 2017 , but the increase did not reach conventional levels of significance $(p=0.10)$.

With the exception of oral naltrexone, the percentage of patients receiving alcohol use disorder medications did not
Table 1 Availability of medications for the treatment of alcohol or opioid use disorder in specialty substance use disorder treatment programs (2014-2017)

\begin{tabular}{|c|c|c|c|c|}
\hline & $2014(n=695)$ & $2017(n=657)$ & $t$ statistic & $p$ value \\
\hline \multicolumn{5}{|l|}{ AUD medications } \\
\hline \multicolumn{5}{|l|}{ Disulfiram } \\
\hline$\%$ programs offering medication & 8.91 & 10.47 & 0.69 & 0.493 \\
\hline$\%$ patients receiving medication & 4.67 & 5.22 & 0.39 & 0.696 \\
\hline \multicolumn{5}{|l|}{ Acamprosate } \\
\hline$\%$ programs offering medication & 7.60 & 8.72 & 0.59 & 0.555 \\
\hline$\%$ patients receiving medication & 6.79 & 10.65 & 0.96 & 0.340 \\
\hline \multicolumn{5}{|l|}{ Oral naltrexone } \\
\hline$\%$ programs offering medication & 13.17 & 16.31 & 1.16 & 0.248 \\
\hline$\%$ patients receiving medication & 7.91 & 13.73 & 2.15 & 0.033 \\
\hline \multicolumn{5}{|l|}{ Injectable naltrexone } \\
\hline$\%$ programs offering medication & 7.45 & 11.08 & 1.63 & 0.104 \\
\hline$\%$ patients receiving medication & 9.08 & 8.44 & 0.21 & 0.833 \\
\hline \multicolumn{5}{|l|}{ OUD medications } \\
\hline \multicolumn{5}{|l|}{ Oral naltrexone } \\
\hline$\%$ programs offering medication & 10.51 & 19.86 & 3.54 & 0.000 \\
\hline$\%$ patients receiving medication & 11.25 & 15.24 & 1.06 & 0.289 \\
\hline \multicolumn{5}{|l|}{ Injectable naltrexone } \\
\hline$\%$ programs offering medication & 10.51 & 16.60 & 2.38 & 0.017 \\
\hline$\%$ patients receiving medication & 8.80 & 11.94 & 1.26 & 0.208 \\
\hline \multicolumn{5}{|l|}{ Buprenorphine in all programs } \\
\hline$\%$ programs offering medication & 29.25 & 35.46 & 1.78 & 0.075 \\
\hline$\%$ patients receiving medication & 14.67 & 15.81 & 0.44 & 0.661 \\
\hline \multicolumn{5}{|l|}{ Methadone in all programs } \\
\hline$\%$ programs offering medication & 8.40 & 10.47 & 1.43 & 0.153 \\
\hline$\%$ patients receiving medication & 83.77 & 73.95 & 1.83 & 0.068 \\
\hline \multicolumn{5}{|l|}{ Methadone in OTPs } \\
\hline$\%$ programs offering medication & 82.61 & 83.99 & 0.31 & 0.758 \\
\hline$\%$ patients receiving medication & 87.80 & 83.65 & 1.19 & 0.235 \\
\hline \multicolumn{5}{|l|}{ Buprenorphine in OTPs } \\
\hline$\%$ programs offering medication & 47.08 & 53.04 & 0.95 & 0.345 \\
\hline$\%$ patients receiving medication & 9.65 & 13.28 & 0.98 & 0.328 \\
\hline
\end{tabular}

Source: Authors' analysis of data from the 2014 and 2017 waves of the National Drug Abuse Treatment System Survey (NDATSS). NDATSS employs a split-panel design with replacement sampling to replace programs that exit the survey and ensure the representativeness of the substance use disorder treatment program population at each wave of data collection. Survey weights are used to account for possible nonresponse bias and to ensure that the sample is representative of the study population. Response rates for both waves are above $85 \%$. $t$ tests examine changes in the proportion of programs offering alcohol and opioid use disorder medications and the percentage of patients receiving alcohol and opioid use disorder medications from 2014 to 2017.

$\mathrm{AUD}=$ alcohol use disorder; OUD = opioid use disorder

Statistically significant results from $t$ tests are noted in italics. 
significantly change from 2014 to 2017 . The average percentage of alcohol use disorder patients receiving medications was lowest for disulfiram $(5.2 \%)$, followed by injectable naltrexone $(8.4 \%)$, and acamprosate $(10.7 \%)$. The average percentage of alcohol use disorder patients receiving oral naltrexone increased from 7.91 to 13.7 ( $p<0.05)$. Compared with earlier studies of privately funded treatment programs, the percentage of alcohol patients receiving medications remained about the same for oral naltrexone but decreased for both disulfiram and acamprosate [36, 83].

\section{Availability of Opioid Use Disorder Medications}

With the exception of methadone, availability of medications for the treatment of opioid use disorder has charted a different trend, increasing substantially over the past decade. A study using 2007-2016 data from National Survey of Substance Abuse Treatment Services (N-SSATS) found that the percentage of all substance use disorder treatment programs offering buprenorphine increased from $14.9 \%$ in 2007 to $25.4 \%$ in 2016 and the percentage offering extended-release injectable naltrexone increased from 9.6 to $20.7 \%$. However, the study could not distinguish between use of naltrexone for alcohol or opioid use disorder treatment [87]. These findings suggest an upward trend in availability of buprenorphine and extendedrelease naltrexone over the past decade. At the same time, use of methadone has remained flat over the past decade, with about $10 \%$ of all specialty substance use disorder treatment programs offering the medication [87].

Only two early studies report the percentage of patients receiving medications for opioid use disorder treatment [36, 70]. Data from 2007 to 2008 showed that about $11 \%$ of primary opioid patients in privately funded treatment programs received oral naltrexone and about $37 \%$ of primary opioid patients received buprenorphine for maintenance treatment. Early research did not examine the percentage of patients receiving methadone in OTPs (see Table 2).

\section{NDATSS: 2014-2017}

The most current data from NDATSS shows continued growth in the availability of naltrexone and buprenorphine for opioid use disorder treatment from 2014 to 2017 (see Table 1). The percentage of specialty treatment programs offering oral naltrexone, injectable naltrexone, and buprenorphine for opioid use disorder treatment significantly increased from 2014 to 2017. The percentage of programs offering oral naltrexone increased from 10.5 to $19.9 \%(p<0.001)$ and the percentage offering injectable naltrexone for opioid use disorder increased from 10.5 to $16.6 \%(p<0.05)$.

The percentage of specialty treatment programs offering buprenorphine also increased from 29.3 to $35.5 \%$; however, the increase was only marginally significant $(p<0.10)$. Data disaggregated by programs type, OTP versus non-OTP, show that buprenorphine availability was substantially higher in OTPs. In 2017 , over half $(53.0 \%)$ of OTPs offered buprenorphine compared to about one third (33.8\%) of nonOTPs. However, the percentage of programs offering methadone did not significantly change (among all programs and among only OTPs).

The percentage of opioid use disorder patients receiving medications did not significantly increase from 2014 to 2017 . About $11.9 \%$ of opioid use disorder patients received injectable naltrexone, $15.2 \%$ received oral naltrexone, and $15.8 \%$ received buprenorphine in 2017. Compared to earlier studies using data from privately funded treatment programs, the percentage of patients receiving oral naltrexone was about the same and the percentage of patients receiving buprenorphine was substantially lower $[36,70]$. This may be explained in part by differences in study methodology.

Finally, the percentage of patients receiving methadone decreased from 2014 to 2017, which may be related to growth in buprenorphine availability in OTPs. Specifically, the percentage of opioid use disorder patients in OTPs receiving methadone decreased by 4.15 percentage points, whereas the percentage receiving buprenorphine increased by 3.63 percentage points. However, these changes were not statistically significant.

In addition to differences based on program funding, other internal and external characteristics of specialty treatment programs have been found to be associated with the availability of alcohol and opioid use disorder medications [36, 60-83]. These factors are treatment program ownership, treatment setting, accreditation, hospital location, staff professionalism and access to physicians, program size, revenues from private insurance, client characteristics, treatment philosophy, and competition in the local labor market. State and federal policy such as Medicaid expansion and Medicaid coverage of medications have also been found to influence medication availability in the specialty treatment system [36, 60-83, 88-95]. See the following studies for more detailed information on these factors: [74, 76, 89, 92, 93, 96-99].

Overall, this body of literature shows a steady decline in the availability of medications for the treatment of alcohol use disorder and an increase in the availability of medications for the treatment of opioid use disorder in the specialty substance use disorder treatment system, with the exception of methadone. Even with increased availability of buprenorphine and injectable naltrexone, the percentage of opioid use disorder patients receiving medications remains low, particularly when considered in light of the increased demand for opioid use disorder treatment. Although alcohol misuse and alcohol use disorder have not been labeled as a public health crisis, there are substantially higher numbers of Americans suffering from alcohol use disorder compared to opioid use disorder as 
Table 2 Availability of buprenorphine-waivered providers (2017-2019)

\begin{tabular}{|c|c|c|c|c|}
\hline & $\begin{array}{l}2017 \\
(n=42,279)\end{array}$ & $\begin{array}{l}2019 \\
(n=59,533)\end{array}$ & $\begin{array}{l}t \\
\text { statistic }\end{array}$ & $p$ value \\
\hline \multicolumn{5}{|l|}{ Total number of waivered providers, $n$} \\
\hline Physician 30-patient waiver & 25,121 & 33,454 & 5.069 & $<0.001$ \\
\hline Physician 100-patient waiver & 8528 & 9100 & 17.993 & $<0.001$ \\
\hline Physician 275-patient waiver & 3698 & 4555 & 4.794 & $<0.001$ \\
\hline PA 30-patient waiver & 969 & 2134 & 12.705 & $<0.001$ \\
\hline PA 100-patient waiver & - & 1494 & - & \\
\hline NP 30-patient waiver & 3721 & 8222 & 26.387 & $<0.001$ \\
\hline NP 100-patient waiver & - & 394 & - & - \\
\hline \multicolumn{5}{|c|}{ Total number of waivered providers per 100,000 persons, mean (sd) } \\
\hline $\begin{array}{l}\text { Physician 30-patient waiver per 100,000 per- } \\
\text { sons }\end{array}$ & $0.011(0.021)$ & $0.010(0.021)$ & 1.471 & 0.141 \\
\hline $\begin{array}{l}\text { Physician 100-patient waiver per 100,000 } \\
\text { persons }\end{array}$ & $0.003(0.013)$ & $0.003(0.012)$ & 10.251 & $<0.001$ \\
\hline $\begin{array}{l}\text { Physician 275-patient waiver per } 100,000 \\
\text { persons }\end{array}$ & $0.002(0.008)$ & $0.001(0.008)$ & 2.720 & 0.007 \\
\hline PA 30-patient waiver per 100,000 persons & $0.0005(0.006)$ & $0.0008(0.007)$ & 6.664 & $<0.001$ \\
\hline PA 100-patient waiver per 100,000 persons & - & $0.0003(0.004)$ & - & - \\
\hline NP 30-patient waiver per 100,000 persons & $0.002(0.011)$ & $0.003(0.013)$ & 14.741 & $<0.001$ \\
\hline NP 100-patient waiver per 100,000 persons & - & $0.00008(0.002)$ & - & - \\
\hline
\end{tabular}

Source: Authors' analysis of the Drug Enforcement Agency list of buprenorphine-waivered physicians from the last quarter of 2017 and the first quarter of 2019. Raw counts of buprenorphine-waivered physicians are presented and rates of buprenorphine-waivered providers per 100,000 persons are calculated. $t$ tests examine changes in the number of buprenorphine-waivered providers and the number of buprenorphine-waivered providers per 100,000 persons from 2017 to 2019 .

$\mathrm{NP}=$ nurse practitioner; $\mathrm{PA}=$ physician's assistant

Statistically significant results from $t$ tests are noted in italics. well as a greater number of annual deaths from excessive alcohol use than from opioid overdose. Thus, the decline in availability of alcohol medications in the specialty treatment system is concerning.

\section{Availability of Substance Use Disorder Medications in Other Treatment Settings and Systems}

With the exception of methadone, medications for the treatment of alcohol and opioid use disorders can be delivered in a variety of other treatment settings and systems outside of the specialty substance use disorder treatment system described above. These include acute care settings (e.g., Emergency Departments), primary care settings (e.g., Community Health Centers), the Veterans Health Administration (VHA), and criminal justice settings. Prescribing of alcohol and opioid medications can also be identified using insurance claims data such as Medicaid, Medicare, and commercial insurance. Although claims data capture a wider range of treatment settings in which medications are delivered (e.g., acute care, primary care, and specialty care settings), they face their own set of limitations [100]. To offer a broader perspective on medication availability in the USA, below we summarize the literature on patient receipt of alcohol and opioid medications in Federally Qualified Health Centers and Community Health Centers, Medicaid and commercial claims data, and the VHA.

\section{Federally Qualified Health Centers and Community Health Centers}

Several studies have documented availability of medications in primary care settings including Federally Qualified Health Centers and networks of Community Health Centers. These studies revealed low rates of alcohol and opioid use disorder treatment medication availability. For example, a recent study of Federally Qualified Health Centers found that only $12.3 \%$ of Federally Qualified Health Centers offered buprenorphine in 2010 [101].

In a study of Community Health Centers participating in an applied research network, Rieckmann and colleagues observed that among patients with alcohol use disorder, $3.2 \%$ had one or more alcohol use disorder treatment medication orders in their electronic health record; among patients with 
opioid use disorder, $29 \%$ had one or more opioid use disorder treatment medication orders in their electronic health record [102]. A study of opioid use disorder patients in 70 Community Health Centers in Oregon and California showed that $32.7 \%$ of patients received buprenorphine [103].

\section{Medicaid and Commercial Claims Data}

A handful of studies have examined receipt of medications for the treatment of alcohol or opioid use disorder using Medicaid or commercial claims data. A recent study using data from the Oregon Medicaid program found that the percentage of patients with an alcohol use disorder diagnosis receiving a medication increased from 2.3\% in 2010 to $3.8 \%$ in 2015 [104]. Similar data from the Oregon Medicaid program showed that the percentage of enrollees with an opioid use disorder diagnosis who received a medication did not significantly change from 2010 to 2016. In 2016, about $15.5 \%$ of enrollees with an opioid use disorder received buprenorphine, $31.2 \%$ received methadone, $2.0 \%$ received oral naltrexone, and $6.3 \%$ received injectable naltrexone [105].

Medicaid claims data from Pennsylvania showed that the percentage of enrollees with an opioid use disorder diagnosis who filled a prescription for buprenorphine increased from $9.8 \%$ in 2007 to $25.2 \%$ in 2012 [106]. Using Medicaid claims data from 14 states (2002-2009), Stein and colleagues found an increase in the number of Medicaid enrollees receiving methadone and buprenorphine. Among all enrollees that received an opioid medication in 2009, $29 \%$ received buprenorphine [100]. Note that patients in this study were not identified by an opioid use disorder diagnosis, but rather by a claim indicating treatment with methadone or a buprenorphine prescription.

A study using data from the Truven Health Analytics MarketScan Commercial Claims Database (IBR Watson Health; New York, New York) found that although the proportion of patients diagnosed with opioid use disorder increased from 2010 to 2014, the percentage of months with an opioid medication among patients with an opioid use disorder decreased over the study period from 25 to $16 \%$ [107]. Taken together, this emerging body of research shows similar trends to studies focusing solely on the specialty treatment system. In particular, the percentage of patients receiving alcohol use disorder medications was substantially lower than patients receiving opioid use disorder medications and the percentage of patients receiving opioid use disorder medications increased prior to 2012, but has remained stagnant since that time.

\section{Veterans Health Administration}

A separate body of research has examined the availability of substance use disorder medications in the VHA [108-112]. Of note, because the VHA is an integrated health care system, it includes specialty substance use disorder treatment programs, primary care settings, and a variety of other inpatient and outpatient care settings. A 2012 study of VHA patients with alcohol use disorder showed that about $2.8 \%$ of alcohol use disorder patients received a medication in 2006 and 3.4\% received a medication in 2009 [108]. A more recent study found that about $5.1 \%$ of all VHA patients with an alcohol use disorder diagnosis received an alcohol use disorder medication in the 2011-2013 time period [110].

Studies on the use of opioid use disorder medications in the VHA show similar trends to the specialty treatment system. From 2004 to 2012, the percentage of VHA patients with opioid use disorder receiving any medication increased from 25.1 to $33.0 \%$. Of the $33 \%$ of VHA patients receiving an opioid use disorder medication in 2012, $18 \%$ received methadone, $17 \%$ received buprenorphine, and $3 \%$ of received naltrexone. However, the percentage of VHA patients with opioid use disorder receiving any medication changed little from 2012 to 2017 . About $34.8 \%$ of VHA patients with opioid use disorder received a medication in 2017. A majority received either methadone or buprenorphine (33.9\%) and less than $1 \%$ received injectable naltrexone [111]. However, the number of OTPs operated by the VHA decreased from 44 in 1973 to 32 in 2018 [111]. Consistent with research conducted outside the VHA, prescribing of medications was substantially lower in primary care settings than in specialty treatment settings within the VHA. Also, similar to findings from the Oregon Medicaid program and commercial claims data, these studies found little change in the percentage of patients receiving opioid use disorder medications in the past decade. Roughly the same percentage of patients $(\sim 15 \%)$ received buprenorphine in the VHA, Oregon Medicaid program, and the specialty substance use disorder treatment system.

Studies of buprenorphine-waivered providers in the VHA show similar findings to studies of non-VHA waivered providers. Although the total number of buprenorphine-waivered providers in the VHA increased from 17 waivered providers in 2003 to 1458 waivered providers in 2018 , approximately $43 \%$ of waivered providers did not prescribe any buprenorphine in the past 180 days. The same study found that waivered VHA providers prescribed well below their patient limits [112].

Overall, this body of literature indicates lower rates of prescribing of opioid and alcohol use disorder medications in primary care settings as compared to specialty treatment settings. Prescribing of buprenorphine was higher than naltrexone and other alcohol use disorder medications, but still fell well below optimal levels. Commonly cited barriers to prescribing of alcohol and opioid use disorder medications in primary care settings include lack of knowledge, time constraints, lack of institutional support, inadequate reimbursement, lack of patient demand, inadequate staffing and resources, lack of behavioral health supports, and philosophical barriers [81, 110, 111, 113-116]. 


\section{Availability of Buprenorphine-Waivered Providers in the USA}

As described above, the existing research shows that buprenorphine is the most widely prescribed substance use disorder treatment medication outside of the specialty substance use disorder treatment system. A growing body of literature examines the availability of buprenorphine-waivered providers , focusing primarily on the characteristics of waivered providers and the geographic distribution of buprenorphine providers [117-125]. Of note, studies utilizing the DEA list of waivered providers cannot determine if a provider actually prescribes the medication, just whether the provider holds the waiver. Thus, these studies overestimate the number of active buprenorphine-waivered providers. For example, Arfken and colleagues found that about $25 \%$ of physicians holding a waiver never prescribed buprenorphine [117].

One of the earliest studies of buprenorphine-waivered physicians observed that by the end of 2008, 15,662 physicians held a waiver to prescribe buprenorphine. About $84 \%$ of physicians held a 30-patient waiver and about $16 \%$ held a $100-$ patient waiver [117]. The study also found that in 2008, the mean number of patients being treated among physicians with at least one buprenorphine patient was 32.45 (locator and DEA list combined) [117].

A recent study of newly buprenorphine-waivered providers found low levels of implementation among this set of providers. The mean number of patients treated in the past month was 26.6 [125]. Among providers with a 30-patient waiver, the mean number of patients was 10.8; among providers with a 100-patient waiver, the mean number of patients was 28.4; and among providers with a 275 -waiver, the mean number of patients was 95.8 . Overall, however, only $13.1 \%$ of all new buprenorphine providers prescribed at or near their patient limit.

A study of buprenorphine prescribing in three states also found that physicians prescribed below their patient limits. The adjusted mean monthly patient census for 30-patient waivered providers was 13.6 and the adjusted mean was 42.9 for 100 patient waivered providers [126]. Similarly, a study by Stein and colleagues revealed that in the seven states with the greatest number of buprenorphine-waivered physicians, the median monthly patient census was 13 patients. Further, $22 \%$ of waivered physicians treated 1 to 3 patients, $49 \%$ treated 4 to 30 patients, $20 \%$ treated 31 to 75 patients, and $9 \%$ treated more than 75 patients monthly [121]. Given that current need for opioid use disorder treatment in the USA far outstrips supply, it is critical that waivered providers prescribe closer to their patient maximum in order to close this treatment gap.

This body of literature also shows that providers holding buprenorphine waivers practice in a mix of both specialty and nonspecialty treatment settings. However, the odds of prescribing buprenorphine after obtaining a waiver were greater for providers practicing in a specialty substance use disorder treatment program or an OTP, compared to a solo office-based practice. Further, the odds of prescribing at or near the patient limit were greater for providers practicing in an OTP, compared to those practicing in an office-based solo practice.

A second set of studies examines the geographic distribution of buprenorphine providers. An early study of county-level availability of waivered physicians revealed that in 2012, less than $50 \%$ of all US counties had at least one buprenorphinewaivered physician. Further, only $2.2 \%$ of all physicians in the USA held a buprenorphine waiver [118]. However, availability may be improving. A study examining county-level availability of buprenorphine-waivered physicians from 2008 to 2011 found that the percentage of US counties that did not have a waivered physician significantly declined from 50.1 to $43.4 \%$. Counties located in the South and Midwest had fewer waivered physicians than counties located in the Northeast $[120,122]$. A more recent study revealed that the percentage of rural counties with no buprenorphine-waivered providers decreased from $67.1 \%$ in 2012 to $56.3 \%$ in 2017 [127]. However, 44\% of all counties in the USA still lacked a buprenorphine prescriber at the end of 2017.

The most recent data available from the DEA shows that the total number of buprenorphine-waivered providers increased from 42,279 in the last quarter of 2017 to 59,533 in the first quarter of 2019-almost a 30\% increase (Table 2). The number of physicians holding 30-patient, 100-patient, and 275-patient waivers significantly increased as well (all $p<0.001$ ). Although the number of physicians per 100,000 persons holding a 30-patient waiver from 2017 to 2019 did not significantly increase, there was a significant increase in the number of physicians per 100,000 persons holding 100 patient and 275-patient waivers $(p<0.05$ and $p<0.001$, respectively). There was also a statistically significant increase in the number of PAs and NPs per 100,000 persons holding a 30-patient wavier (both $p<0.001$ ). In the first quarter of 2019 , 1494 PAs held a 100-patient waiver and 394 NPs held a 100patient waiver.

Overall, there has been tremendous growth in the number of buprenorphine-waivered providers over the past 15 years. In 2004, an estimated 3293 physicians held a waiver to prescribe buprenorphine and by the first quarter an estimated 47,109 physicians held a buprenorphine waiver. Additionally, in 2019, 3628 PAs and 8616 NPs held buprenorphine waivers. Recent changes (2017 to 2019) in the number of waivered providers per 100,000 persons has occurred among physicians seeking 100-patient and 275patient waivers, rather than in physicians seeking 30-patient waivers, as well as among PAs and NPs. Further, studies estimating the number of patients served by buprenorphinewaivered physicians consistently show that a majority of waivered physicians are prescribing well below patient limits $[121,125,126]$. 
This literature also indicates that geographic disparities in access to waivered providers continue. In $2017,76.8 \%$ of urban counties had at least one buprenorphine-waivered provider, whereas only $43.7 \%$ of rural counties had at least one waivered provider [127].

\section{Strategies to Improve the Availability of Alcohol and Opioid Use Disorder Medications in the USA}

Despite growth in the availability of buprenorphine, oral naltrexone, and injectable naltrexone for the treatment of opioid use disorder, overall rates of medication availability in the specialty substance use disorder treatment system remain low. In the midst of a public health crisis, with annual deaths from excessive alcohol consumption numbering approximately 88,000 and drug overdose deaths exceeding 70,000, the question remains: Why is availability of evidence-based medications for the treatment of alcohol and opioid use disorder so low? The answer to this question is multifaceted and has been the subject of numerous studies identifying barriers to use of alcohol and opioid use disorder medications. The major categories of barriers are educational and training barriers, stigma and attitudinal barriers, geographic and logistical barriers, barriers related to delivery system fragmentation, regulatory barriers, and barriers related to health insurance coverage and reimbursement. We discuss a number of these central challenges and potential strategies for improvement below. See the following studies for more detailed information regarding barriers to availability of substance use disorder treatment medications: [15, 76, 96-98, 114, 116, 128].

First, training in addiction medicine should be integrated into medical school curricula across the county. In 2011, the first accredited residency programs in addiction medicine were introduced in the USA. There are now approximately 65 accredited residency programs in addiction medicine [129]. However, this is not enough. A more comprehensive approach is needed which includes training in addiction treatment for all medical students. Prior research shows that physicians often lack knowledge of substance use disorder treatment medications and the skills necessary to prescribe these medications and effectively monitor patients $[38,81,114$, 130-132]. Physicians may also view treating patients for substance use disorder as outside the scope of their responsibilities as primary care providers [38]. Providing training in addiction medicine to all medical students may bolster both screening and treatment of substance use disorder in nonspecialty treatment settings. Similar training should be incorporated in the curricula of other healthcare professionals including nursing and pharmacy as well as in schools of social work across the country $[97,133,134]$. These front-line providers typically have greater opportunities to interact with patients than physicians, particularly in rural areas [135-138]. Outside of the healthcare system, education and training in criminal justice settings is also critical $[15,98]$.

Second, the substance use disorder treatment workforce itself must be formally educated on the benefits of medication treatment [54, 139-143]. Although it may seem counterintuitive, many counselors employed in the specialty substance use disorder treatment system are themselves in recovery and oppose the use of medications [139-141]. The use of medications is considered by many counselors and other treatment professionals as inconsistent with the 12-step or abstinence-based treatment orientation, which has historically been dominated the specialty substance use disorder treatment system [80, 81, 140-142, 144].

Third, reducing stigma surrounding substance use disorder treatment in general and the use of medications in substance use disorder treatment is necessary to increase medication availability $[15,145]$. This is particularly problematic for buprenorphine and methadone, as they are often viewed inaccurately as replacing one addiction with another due to their agonist properties $[52,146]$. In contrast to other prescription and illicit opioids, methadone and buprenorphine have a slower rate of entry into the brain compared to other prescription and illicit opioids, which limits their rewarding effects [146]. Policymakers, the general public, mainstream healthcare providers, as well as those in the specialty substance use disorder treatment system continue to hold negative perceptions of medication treatment [15, 96-98, 140, 141]. If not addressed, stigma and negative perceptions of medications will continue to dampen efforts to improve availability of alcohol and opioid use disorder treatment medications in the USA.

Fourth, reducing geographic disparities in access to medication treatment is imperative. Although there has been substantial growth in buprenorphine-waivered providers, there are continued geographic disparities in access to waivered providers [121, 125-127]. In particular, studies show more limited availability of buprenorphine-waivered providers in the South and Midwest regions of the USA, as well as in rural counties [119, 122, 127, $147,148]$. Notably, growth in availability of buprenorphine in the specialty treatment system is concentrated in OTPs, which are limited in number $(\sim 1300$ of 13,400 specialty substance use disorder treatment programs) and are geographically concentrated in urban areas $[120,122]$. In addition, there is evidence that the majority of OTPs lack the capacity to treat additional patients [124].

Implementation of alcohol and opioid use disorder medications in Federally Qualified Health Centers could dramatically reduce disparities in access to medications. Federally Qualified Health Centers serve as the safety net provider for under-insured and uninsured Americans - serving about 23 million Americans annually in about 13,000 sites nationwide. These health centers provide an important opportunity to treat low-income Americans, who are disproportionately affected by substance use disorder [149, 150], and to reduce geographic disparities in 
access to medications, as Federally Qualified Health Centers are located in many rural and underserved areas.

Fifth, greater integration of care for Americans with substance use disorder is needed. Historically, the specialty substance use disorder treatment system has operated outside of mainstream health care, which has resulted in fragmented care for this patient population $[15,145]$. Several integrated care models are currently being implemented across the country to address this issue. One of the first studies to test a collaborative care model for the treatment alcohol and opioid use disorder in primary care settings (SUMMIT) found that compared to usual care, the collaborative care intervention showed an increase in the proportion of patients receiving evidencebased treatment and an increase the number of patients achieving self-reported abstinence from opioids or alcohol use at 6 months [151-153]. A second promising model, the Massachusetts Collaborative Care Model for the delivery of buprenorphine in primary care (OBOT-B), is distinguished by the central role of a nurse care manager as part of a multidisciplinary treatment team [154]. Statewide implementation of OBOT-B has resulted in a dramatic increase in the number of waivered physicians as well as an increase in annual admissions [154].

Another popular model integrating care for opioid use disorder patients is the hub and spoke model which originated in Vermont [155]. Vermont's hub and spoke system is comprised of 7 regional "hubs" that offer buprenorphine or methadone and 77 local "spokes" or primary care settings that offer buprenorphine or naltrexone [156]. Early results showed that implementation of the model was associated with an increase in Vermont's capacity to treat opioid use disorder, evidenced by an increase in waivered physicians and the number of patients served per waivered physician [155]. Further, patients receiving treatment within Vermont's hub and spoke system reported lower opioid use as well as reductions in overdoses, visits to the emergency department, contact with police, and family conflict and improvements in several areas of life satisfaction and mood [156]. Several states are currently implementing hub and spoke models, including Washington and California [157, 158].

Sixth, revising federal, state, and local regulations on the dispensing of methadone and prescribing of buprenorphine is necessary. Allowing methadone to be dispensed outside of OTPs would greatly increase access to this medication. For example, if methadone were dispensed in Federally Qualified Health Centers, the number of methadone providers could increase from about 1300 to more than 10,000. In addition, there are calls to remove the requirement to obtain a DATA 2000 waiver to prescribe buprenorphine $[134,159,160]$. There are no such requirements to prescribe other opioid medications or to prescribe buprenorphine for pain managementother than holding a DEA license, which is required to prescribe any scheduled narcotic in the USA. Further, although
PAs and NPs have been allowed under federal law to obtain buprenorphine waivers since 2016, state scope of practice regulations do not allow for this in every state. As of September 2018, 24 states prohibited NPs from prescribing buprenorphine without waivered physician oversight and 28 states imposed restrictions on PA prescribing [161]. A recent study found that more restrictive scope of practice laws were associated with fewer NPs with buprenorphine waivers; however, no significant effect was found for PAs and scope of practice laws [161]. Less restrictive NP and PA scope of practice laws are particularly important in rural areas where NPs and PAs serve a critical role in healthcare service delivery [162].

Seventh, improving insurance coverage of substance use disorder treatment medications, reducing or eliminating utilization controls, and improving reimbursement rates will also improve availability of medications. For example, in 2017, 11 state Medicaid programs did not cover methadone for the treatment of opioid use disorder [163]. Although all state Medicaid programs do cover buprenorphine, $69 \%$ require prior authorization, which is associated with lower odds of offering the medication among specialty substance use disorder treatment programs $[89,163]$. Similarly, approximately $65 \%$ of Medicare Part D plans restricted coverage for all buprenorphine products in 2018. In addition, the Medicare program does not currently cover treatment services delivered in OTPs, which greatly limits access to methadone for this growing segment of the population. Private insurers also place similar limits on buprenorphine and methadone treatment for opioid use disorder [164].

Eighth, although the federal government has allocated funds to states to address the opioid crisis through the $21 \mathrm{st}$ Century Cures and SUPPORT Act legislation, experts argue additional funding is needed. It will require a more substantial investment from the federal government. One expert estimated that $\$ 60$ billion over a period of 10 years is needed to improve opioid use disorder prevention and treatment in the USA. Francis Collins reported that $\$ 500$ million a year is needed for opioid use disorder research alone [165].

Finally, continued development of novel medications and formulations to treat substance use disorder more effectively are needed, particularly for the treatment of alcohol use disorder [38]. The limited to moderate efficacy of the current FDAapproved alcohol use disorder medications likely contributes to their declining rates of use compared to opioid use disorder medications. For example, disulfiram does not relieve cravings for alcohol and naltrexone and acamprosate are not effective in all patients $[38,166]$. Additionally, no alcohol use disorder medication has achieved "blockbuster" status [39, 41, 167, 168]. Development of novel alcohol use disorder medications has also faced the additional barrier of overcoming the so-called "valley of death," i.e., the transition from preclinical to clinical testing $[167,168]$. 


\section{Recent Progress in Substance Use Disorder Medication Development in the USA}

The National Institute on Drug Abuse and the National Institute on Alcoholism and Alcohol Abuse continue to devote significant resources to the development of medications for the treatment of substance use disorder. Clinical research aimed at the development of medications to treat alcohol use disorder indicates that ABT-436, aripiprazole, prazosin, doxazosin, zonisamide, nalmefene, baclofen, topirimate, ondansetron, gabapentin, and varenicline currently show the greatest promise [166, 169]. In fact, both nalmefene and baclofen are approved for the treatment of alcohol use disorder in other countries. Several other medications and compounds are in the preclinical or preliminary proofof-concept phase of development for the treatment of alcohol use disorder (e.g., D-cycloserine, N-acetylcysteine, the hormone oxytocin) [166].

The most recent advances in the development of medications for the treatment of opioid use disorder are long-lasting buprenorphine implants and weekly and monthly subcutaneous depot formulations of buprenorphine [170, 171]. In addition, the National Institute on Drug Abuse recently issued a list of their ten most wanted medication development priorities for the rapid development of therapeutics in response to the opioid crisis. These include the following: 1) orexin-1 or 1/ 2 antagonists or NAMs; 2) kappa opioid antagonists or NAMs; 3) GABA-B agonists or PAMs; 4) muscarinic M5 antagonists or NAMs; 5) AMPA antagonists, NAMs, or PAMs; 6) NOP/ORL agonists, antagonists, NAMs, or PAMs; 7) mGluR2/3 agonists or PAMs; 8) ghrelin antagonists or NAMs; 9) dopamine D3 partial agonists, PAMs, antagonists, or NAMs; and 10) cannabinoid CB-1 antagonists or NAMs [172].

\section{Conclusion}

To meet increased need for substance use disorder treatment in the USA, it is essential that Americans have access to highquality evidence-based treatment. Improving the availability of medications to treat alcohol and opioid use disorder is critical to address the current opioid crisis and to mitigate the harms of excessive drinking. Addressing the numerous barriers to receipt of these medications will require a comprehensive approach and perhaps an overhaul of the current substance use disorder treatment delivery system in the USA.

\section{References}

1. Substance Abuse and Mental Health Services Administration. Key substance use and mental health indicators in the United
States: results from the 2016 National Survey on Drug Use and Health. Rockville: Center for Behavioral Health Statistics and Quality, Substance Abuse and Mental Health Services Administration; 2017.

2. Florence CS, Zhou C, Luo F, Xu L. The economic burden of prescription opioid overdose, abuse, and dependence in the united states, 2013. Med Care 2016;54(10):901-6.

3. Ahmad F, Rossen L, Spencer M, Warner M, Sutton P. Provisional drug overdose death counts; 2018. Available from: https://www. cdc.gov/nchs/nvss/vsrr/drug-overdose-data.htm. Accessed 1 June 2019

4. Sacks JJ, Gonzales KR, Bouchery EE, Tomedi LE, Brewer RD. 2010 National and State Costs of Excessive Alcohol Consumption. Am J Prev Med 2015;49(5):e73-e9.

5. Stahre M, Roeber J, Kanny D, Brewer RD, Zhang X. Contribution of excessive alcohol consumption to deaths and years of potential life lost in the United States. Prev Chronic Dis 2014;11:E109.

6. Mattick RP, Breen C, Kimber J, Davoli M. Buprenorphine maintenance versus placebo or methadone maintenance for opioid dependence. Cochrane Database Syst Rev 2014(2):CD002207.

7. Amato L, Minozzi S, Davoli M, Vecchi S. Psychosocial combined with agonist maintenance treatments versus agonist maintenance treatments alone for treatment of opioid dependence. Cochrane Database Syst Rev. 2011(10):Cd004147.

8. Amato L, Minozzi S, Davoli M, Vecchi S. Psychosocial and pharmacological treatments versus pharmacological treatments for opioid detoxification. Cochrane Database Syst Rev. 2011(9):Cd005031.

9. Amass L, Ling W, Freese TE, Reiber C, Annon JJ, Cohen AJ, et al. Bringing buprenorphine-naloxone detoxification to community treatment providers: the NIDA Clinical Trials Network field experience. Am J Addict 2004;13 Suppl 1:S42-66.

10. Krupitsky E, Nunes EV, Ling W, Illeperuma A, Gastfriend DR, Silverman BL. Injectable extended-release naltrexone for opioid dependence. Lancet. 2011;378(9792):665; author reply 6.

11. Johansson BA, Berglund M, Lindgren A. Efficacy of maintenance treatment with naltrexone for opioid dependence: a metaanalytical review. Addiction. 2006;101(4):491-503.

12. Comer SD, Sullivan MA, Yu E, Rothenberg JL, Kleber HD, Kampman K, et al. Injectable, sustained-release naltrexone for the treatment of opioid dependence: a randomized, placebocontrolled trial. Arch Gen Psychiatry 2006;63(2):210-8.

13. Fiellin DA, Pantalon MV, Chawarski MC, Moore BA, Sullivan LE, O'Connor PG, et al. Counseling plus buprenorphine-naloxone maintenance therapy for opioid dependence. N Engl J Med 2006;355(4):365-74.

14. Ziedonis DM, Amass L, Steinberg M, Woody G, Krejci J, Annon JJ, et al. Predictors of outcome for short-term medically supervised opioid withdrawal during a randomized, multicenter trial of buprenorphine-naloxone and clonidine in the NIDA clinical trials network drug and alcohol dependence. Drug Alcohol Depend 2009;99(1-3):28-36.

15. National Academies of Sciences E, and Medicine. Medications for opioid use disorder save lives. Washington, DC; 2019.

16. Bouza C, Angeles M, Munoz A, Amate JM. Efficacy and safety of naltrexone and acamprosate in the treatment of alcohol dependence: a systematic review. Addiction. 2004;99:811-28.

17. O'Malley SS, Jaffe A, Chang G, Schottenfeld RS, Meyer RE, Rounsaville BJ. Naltrexone and coping skills therapy for alcohol dependence: a controlled study. Arch Gen Psychiatry 1992;49:881-7.

18. Rosner S, Hackl-Herrwerth A, Lehert LS, Vecchi S, Soyka M. Acamprosate for alcohol dependence. Cochrane Database Syst Rev. 2011(9).

19. Rosner S, Hackl-Herrwerth A, Lehert LS, Vecchi S, Srisurapanont M, Soyka M. Opioid antagonists for alcohol dependence. Cochrane Database Syst Rev 2010(12). 
20. Srisurapanont M, Jarusuraisin N. Opioid antagonists for alcohol dependence. Cochrane Database Systematic Reviews. 2005.

21. Volpicelli JR, Alterman AI, Hayashida M, O'Brien C. Naltrexone in the treatment of alcohol dependence. Arch Gen Psychiatry 1992;49:876-80.

22. Volpicelli JR, Watson NT, King AC, Sherman CE, O'Brien CP. Effect of naltrexone on alcohol "high" in alcoholics. Am J Psychiatr 1995;152:613-5.

23. Maisel NC, Blodgett JC, Wilbourne PL, Humphreys K, Finney JW. Meta-analysis of naltrexone and acamprosate for treating alcohol use disorders: when are these medications most helpful? Addiction. 2013;108(2):275-93.

24. Garbutt JC, Kranzler HR, O'Malley SS, Gastfriend DR, Pettinati HM, Silverman BL, et al. Efficacy and tolerability of long-acting injectable naltrexone for alcohol dependence: a randomized controlled trial. J Am Med Assoc 2005;293:1617-25.

25. O'Malley S, Garbutt JC, Gastfriend DR, Qunming D, Kranzler HR. Efficacy of extended-release naltrexone in alcoholdependent patients who are abstinent prior to treatment. J Clin Psychopharmacol 2007;27:507-12.

26. Kranzler HR, Wesson DR, Billot L. Naltrexone depot for treatment of alcohol dependence: a multicenter, randomized, placebo controlled clinical trial. Alcohol Clin Exp Res 2004;28:1051-9.

27. Gastfriend DR, Dong Q, Loewy J, Silverman B, Ehrich EW. Effect of long-acting injectable naltrexone on durability of drinking outcomes [Abstract]. Alcohol Clin Exp Res. 2005;29(5 Suppl):77A.

28. Soyka M, J C Use of acamprosate and opioid antagonists in the treatment of alcohol dependence: a European perspective. Am J Addict. 2003;12(Supplement 1):S69-S80.

29. O'Brien C, Cornish JW. Naltrexone for probationers and parolees. J Subst Abus Treat 2006;31(2):107-11.

30. Klemperer EM, Hughes JR, Naud S. Study characteristics influence the efficacy of substance abuse treatments: a meta-analysis of medications for alcohol use disorder. Drug Alcohol Depend 2018;190:229-34.

31. Oslin DW, Leong SH, Lynch KG, Berrettini W, O'Brien CP, Gordon AJ, et al. Naltrexone vs placebo for the treatment of alcohol dependence: a randomized clinical trial. JAMA Psychiatry 2015;72(5):430-7.

32. Brewer C, Meyers RJ, Johnsen J. Does disulfiram help to prevent relaspe in alcohol abuse? CNS Drugs 2000;14(5):329-41.

33. Chick J, Gough K, Falkowski W, Kershaw P, Hore B, Mehta B, et al. Disulfiram treatment of alcoholism. Br J Psychiatry 1992;161:84-9.

34. Fuller RK, Gordis E. Does disulfiram have a role in alcoholism treatment today? Addiction. 2004;99(1):21-4.

35. Suh JJ, Pettinati HM, Kampman KM, O'Brien CP. The status of disulfiram: a half of a century later. J Clin Psychopharmacol 2006;26(3):290-302.

36. Knudsen HK, Abraham AJ, Roman PM. Adoption and implementation of medications in addiction treatment programs. J Addict Med 2011;5(1):21-7.

37. Substance Abuse and Mental Health Services Administration. Treatment Episode Data Set (TEDS): 2005-2015, National admissions to substance abuse treatment services. Rockville: Center for Behavioral Health Statistics and Quality, Substance Abuse and Mental Health Services Administration; 2017.

38. Lyon J. More treatments on deck for alcohol use disorder. JAMA. 2017;317(22):2267-9.

39. Litten RZ, Wilford BB, Falk DE, Ryan ML, Fertig JB. Potential medications for the treatment of alcohol use disorder: an evaluation of clinical efficacy and safety. Subst Abus 2016;37(2):286-98.

40. Vocci F, Ling W. Medications development: successes and challenges. Pharmacol Ther 2005;108(1):94-108.
41. Litten RZ, Falk DE, Ryan ML, Fertig JB. Discovery, development, and adoption of medications to treat alcohol use disorder: goals for the phases of medications development. Alcohol Clin Exp Res 2016;40(7):1368-79.

42. Rogers EM. Diffusion of Innovations. New York: Free Press; 2003.

43. Kranzler HR, Soyka M. Diagnosis and Pharmacotherapy of alcohol use disorder: a review. JAMA. 2018;320(8):815-24.

44. Kennedy WK, Leloux M, Kutscher EC, Price PL, Morstad AE, Carnahan RM. Acamprosate. Expert Opin Drug Metab Toxicol 2010;6(3):363-80.

45. Mann K, Lehert P, Morgan MY. The efficacy of acamprosate in the maintenance of abstinence in alcohol-dependent individuals: results of a meta-analysis. Alcohol Clin Exp Res 2004;28:51-63.

46. Kranzler HR, Van Kirk J. Efficacy of naltrexone and acamprosate in alcoholism treatment: a meta-analysis. Alcohol Clin Exp Res 2001;25:1335-41.

47. Koob GF, Mason BJ, De Witte P, Littleton J, Siggins GR. Potential neuroprotective effects of acamprosate. Alcohol Clin Exp Res 2002;26(4):586-92.

48. Mason BJ, Goodman AM, Dixon RM, Hameed MH, Hulot T, Wesnes K, et al. A pharmacokinetic and pharmacodynamic drug interaction study of acamprosate and naltrexone. Neuropsychopharmacology. 2002;27(4):596-606.

49. Ray LA, Hutchison KE, Ashenhurst JR, Morrow AL. Naltrexone selectively elevates GABAergic neuroactive steroid levels in heavy drinkers with the Asp40 allele of the OPRM1 gene: a pilot investigation. Alcohol Clin Exp Res 2010;34(8):1479-87.

50. Minozzi S, Amato L, Vecchi S, Davoli M, Kirchmayer U, Verster A. Oral naltrexone maintenance treatment for opioid dependence. Cochrane Database Syst Rev. 2011(2):CD001333.

51. Gastfriend DR. A pharmaceutical industry perspective on the economics of treatments for alcohol and opioid use disorders. Ann N Y Acad Sci 2014;1327:112-30.

52. Volkow ND, Frieden TR, Hyde PS, Cha SS. Medication-assisted therapies - tackling the opioid-overdose epidemic. N Engl J Med 2014;370(22):2063-6.

53. Malone M, McDonald R, Vittitow A, Chen J, Obi R, Schatz D, et al Extended-release vs. oral naltrexone for alcohol dependence treatment in primary care (XON). Contemp Clin Trials 2019;81:102-9.

54. Alanis-Hirsch K, Croff R, Ford JH, 2nd, Johnson K, Chalk M, Schmidt L, et al. Extended-release naltrexone: a qualitative analysis of barriers to routine use. J Subst Abus Treat 2016;62:68-73.

55. Sullivan MA, Bisaga A, Pavlicova M, Carpenter KM, Choi CJ, Mishlen K, et al. A randomized trial comparing extended-release injectable suspension and oral naltrexone, both combined with behavioral therapy, for the treatment of opioid use disorder. Am J Psychiatry 2019;176(2):129-37.

56. Center for Substance Abuse Treatment. The Determinations Report: a Report on the Physician Waiver Program Established by the Drug Addiction Treatment Act of 2000 ("DATA"). Rockville: Substance Abuse and Mental Health Services Administration \& U.S. Department of Health and Human Services; 2006.

57. Minozzi S, Amato L, Vecchi S, Davoli M, Kirchmayer U, Verster A. Oral naltrexone maintenance treatment for opioid dependence. Cochrane Database Syst Rev. 2011(4):CD001333.

58. Volkow ND, Wargo EM. Overdose prevention through medical treatment of opioid use disorders. Ann Intern Med 2018;169(3):190-2.

59. American Society of Addiction Medicine. The ASAM national practice guideline for the use of medications in the treatment of addiction involving opioid use. 2015.

60. Ducharme LJ, Roman PM. Opioid treatment programs in the Clinical Trials Network: representativeness and buprenorphine adoption. J Subst Abus Treat 2009;37(1):90-4.

61. Knudsen HK, Ducharme LJ, Roman PM. The adoption of medications in substance abuse treatment: associations with 
organizational characteristics and technology clusters. Drug Alcohol Depend 2007;87(2-3):164-74.

62. Ducharme LJ, Abraham AJ. State policy influence on the early diffusion of buprenorphine in community treatment programs. Subst Abuse Treatment Prev Policy. 2008;3:17.

63. Knudsen HK, Ducharme LJ, Roman PM. Early adoption of buprenorphine in substance abuse treatment centers: data from the private and public sectors. J Subst Abus Treat 2006;30(4):363-73.

64. Heinrich CJ, Hill CJ. Role of state policies in the adoption of naltrexone for substance abuse treatment. Health Serv Res 2008;43(3):951-70.

65. Heinrich CJ, Cummings GR. Adoption and diffusion of evidencebased addiction medications in substance abuse treatment. Health Serv Res 2014;49(1):127-52.

66. Abraham AJ, Roman PM. Early adoption of injectable naltrexone for alcohol-use disorders: findings in the private-treatment sector. J Stud Alcohol Drugs 2010;71(3):460-6.

67. Abraham AJ, Knudsen HK, Rieckmann T, Roman PM. Disparities in access to physicians and medications for the treatment of substance use disorders between publicly and privately funded treatment programs in the United States. J Stud Alcohol Drugs 2013;74:258-65.

68. Abraham AJ, Knudsen HK, Roman PM. A longitudinal examination of alcohol pharmacotherapy adoption in substance use disorder treatment programs: patterns of sustainability and discontinuation. J Stud Alcohol Drugs 2011;72(4):669-77.

69. Abraham AJ, Knudsen HK, Rothrauff TC, Roman PM. The adoption of alcohol pharmacotherapies in the Clinical Trials Network: the influence of research network participation. J Subst Abus Treat 2010;38(3):275-83.

70. Roman PM, Johnson JA. Adoption and implementation of new technologies in substance abuse treatment. J Subst Abus Treat 2002;22(4):211-8.

71. Koch AL, Arfken CL, Schuster CR. Characteristics of U.S. substance abuse treatment facilities adopting buprenorphine in its initial stage of availability. Drug Alcohol Depend 2006;83(3):274-8.

72. Oser CB, Roman PM. Organizational-level predictors of adoption across time: naltrexone in private substance-use disorders treatment centers. J Stud Alcohol Drugs 2007;68(6):852-61.

73. Oser CB, Roman PM. A categorical typology of naltrexoneadopting private substance abuse treatment centers. J Subst Abus Treat 2008;34(4):433-42.

74. Knudsen HK, Roman PM, Oser CB. Facilitating factors and barriers to the use of medications in publicly funded addiction treatment organizations. J Addict Med 2010;4(2):99-107.

75. Knudsen HK, Abraham AJ. Perceptions of the state policy environment and adoption of medications in the treatment of substance use disorders. Psychiatr Serv 2012;63(1):19-25.

76. Knudsen HK, Abraham AJ, Oser CB. Barriers to the implementation of medication-assisted treatment for substance use disorders: the importance of funding policies and medical infrastructure. Eval Program Plan 2011;34(4):375-81.

77. Fuller BE, Rieckmann T, McCarty D, Smith KW, Levine H. Adoption of naltrexone to treat alcohol dependence. J Subst Abus Treat 2005;28(3):273-80.

78. Wallack SS, Thomas CP, Martin TC, Chilingerian J, Reif S. Substance abuse treatment organizations as mediators of social policy: slowing the adoption of a congressionally approved medication. J Behav Health Serv Res 2008;37(1):64-78.

79. Friedmann PD, Jiang L, Alexander JA. Top manager effects on buprenorphine adoption in outpatient substance abuse treatment programs. J Behav Health Serv Res 2010;37(3):322-37.

80. Knudsen HK, Ducharme LJ, Roman PM, Link T. Buprenorphine diffusion: the attitudes of substance abuse treatment counselors. J Subst Abus Treat 2005;29(2):95-106.
81. Thomas CP, Wallack SS, Lee S, McCarty D, Swift R. Research to practice: adoption of naltrexone in alcoholism treatment. J Subst Abus Treat 2003;24(1):1-11.

82. Knudsen HK, Roman PM, Ducharme LJ, Johnson JA. Organizational predictors of pharmocological innovation adoption: the case of disulfiram. J Drug Issues 2005;35(3):559-73.

83. Ducharme LJ, Knudsen HK, Roman PM. Trends in the adoption of medications for alcohol dependence. J Clin Psychopharmacol 2006;26 Suppl 1:S13-9.

84. Substance Abuse and Mental Health Services Administration. National Survey of Substance Abuse Treatment Services (NSSATS). Bethesda: SAMHSA; 2017.

85. Knudsen HK, Abraham AJ, Johnson JA, Roman PM. Buprenorphine adoption in the National Drug Abuse Treatment Clinical Trials Network. J Subst Abus Treat 2009;37(3):307-12.

86. Andrews CM, D'Aunno TA, Pollack HA, Friedmann PD. Adoption of evidence-based clinical innovations: the case of buprenorphine use by opioid treatment programs. Med Care Res Rev 2014;71(1):43-60.

87. Mojtabai R, Mauro C, Wall MM, Barry CL, Olfson M. Medication treatment for opioid use disorders in substance use treatment facilities. Health Aff (Millwood) 2019;38(1):14-23.

88. Abraham AJ, Andrews CM, Grogan CM, Pollack HA, D'Aunno T, Humphreys K, et al. State-targeted funding and technical assistance to increase access to medication treatment for opioid use disorder. Psychiatr Serv 2018;69(4):448-55.

89. Andrews CM, Abraham AJ, Grogan CM, Westlake MA, Pollack HA, Friedmann PD. Impact of Medicaid restrictions on availability of buprenorphine in addiction treatment programs. Am J Public Health 2019;109(3):434-6.

90. Maclean JC, Saloner B. The effect of public insurance expansions on substance use disorder treatment: evidence from the Affordable Care Act. 2017.

91. Meinhofer A, Witman AE. The role of health insurance on treatment for opioid use disorders: evidence from the Affordable Care Act Medicaid expansion. J Health Econ 2018;60:177-97.

92. Andrews CM, Pollack HA, Abraham AJ, Grogan CM, Bersamira CS, D'Aunno T, et al. Medicaid coverage in substance use disorder treatment after the Affordable Care Act. J Subst Abus Treat 2019;102(3):1-7.

93. Garner BR. Research on the diffusion of evidence-based treatments within substance abuse treatment: a systematic review. J Subst Abus Treat 2009;36(4):376-99.

94. Abraham AJ, Andrews CM, Grogan CM, D'Aunno T, Humphreys KN, Pollack HA, et al. The Affordable Care Act transformation of substance use disorder treatment. Am J Public Health 2017;107(1):31-2.

95. Mark TL, Lubran R, McCance-Katz EF, Chalk M, Richardson J. Medicaid coverage of medications to treat alcohol and opioid dependence. J Subst Abus Treat 2015;55:1-5.

96. Roman PM, Abraham AJ, Knudsen HK. Using medicationassisted treatment for substance use disorders: evidence of barriers and facilitators of implementation. Addict Behav 2011;36(6): 584-9.

97. Oliva EM, Maisel NC, Gordon AJ, Harris AH. Barriers to use of pharmacotherapy for addiction disorders and how to overcome them. Curr Psychiatry Rep 2011;13(5):374-81.

98. Sharma A, Kelly SM, Mitchell SG, Gryczynski J, O'Grady KE, Schwartz RP. Update on barriers to pharmacotherapy for opioid use disorders. Curr Psychiatry Rep 2017;19(6):35.

99. Andrews CM, Grogan CM, Westlake MA, Abraham AJ, Pollack HA, D'Aunno TA, et al. Do benefits restrictions limit Medicaid acceptance in addiction treatment? Results from a national study. J Subst Abus Treat 2018;87:50-5.

100. Stein BD, Dick AW, Sorbero M, Gordon AJ, Burns RM, Leslie $\mathrm{DL}$, et al. A population-based examination of trends and 
disparities in medication treatment for opioid use disorders among Medicaid enrollees. Subst Abus 2018;39(4):419-25.

101. Jones EB. Medication-assisted opioid treatment prescribers in Federally Qualified Health Centers: capacity lags in rural areas. J Rural Health 2018;34(1):14-22.

102. Rieckmann T, Muench J, McBurnie MA, Leo MC, Crawford P, Ford D, et al. Medication-assisted treatment for substance use disorders within a national community health center research network. Subst Abus 2016;37(4):625-34.

103. Rieckmann TR, Gideonse N, Risser A, DeVoe JE, Abraham AJ. Treating opioid dependence with buprenorphine in the safety net: critical learning from clinical data. J Behav Health Serv Res 2017;44(3):351-63.

104. McCarty D, Gu Y, Renfro S, Baker R, Lind BK, McConnell KJ. Access to treatment for alcohol use disorders following Oregon's health care reforms and Medicaid expansion. J Subst Abus Treat 2018;94:24-8.

105. McCarty D, Gu Y, Mcllveen JW, Lind BK. Medicaid expansion and treatment for opioid use disorders in Oregon: an interrupted time-series analysis. Addict Sci Clin Pract 2019;14(1):31.

106. Gordon AJ, Lo-Ciganic WH, Cochran G, Gellad WF, Cathers T, Kelley D, et al. Patterns and Quality of buprenorphine opioid agonist treatment in a large Medicaid program. J Addict Med 2015;9(6):470-7.

107. Morgan JR, Schackman BR, Leff JA, Linas BP, Walley AY. Injectable naltrexone, oral naltrexone, and buprenorphine utilization and discontinuation among individuals treated for opioid use disorder in a United States commercially insured population. J Subst Abus Treat 2018;85:90-6.

108. Harris AH, Oliva E, Bowe T, Humphreys KN, Kivlahan DR, Trafton JA. Pharmacotherapy of alcohol use disorders by the Veterans Health Administration: patterns of receipt and persistence. Psychiatr Serv 2012;63(7):679-85.

109. Harris AH, Kivlahan DR, Bowe T, Humphreys KN. Pharmacotherapy of alcohol use disorders in the Veterans Health Administration. Psychiatr Serv 2010;61(4):392-8.

110. Williams EC, Gupta S, Rubinsky AD, Glass JE, Jones-Webb R, Bensley KM, et al. Variation in receipt of pharmacotherapy for alcohol use disorders across racial/ethnic groups: a national study in the U.S. Veterans Health Administration. Drug Alcohol Depend 2017;178:527-33.

111. Wyse JJ, Gordon AJ, Dobscha SK, Morasco BJ, Tiffany E, Drexler K, et al. Medications for opioid use disorder in the Department of Veterans Affairs (VA) health care system: historical perspective, lessons learned, and next steps. Subst Abus 2018;39(2):139-44.

112. Valenstein-Mah H, Hagedorn H, Kay CL, Christopher ML, Gordon AJ. Underutilization of the current clinical capacity to provide buprenorphine treatment for opioid use disorders within the Veterans Health Administration. Subst Abus 2018;39(3):286-8.

113. Harris AH, Ellerbe L, Reeder RN, Bowe T, Gordon AJ, Hagedorn H, et al. Pharmacotherapy for alcohol dependence: perceived treatment barriers and action strategies among Veterans Health Administration service providers. Psychol Serv 2013;10(4):410-9.

114. Mark TL, Kranzler HR, Song X. Understanding US addiction physicians' low rate of naltrexone prescription. Drug Alcohol Depend 2003;71(3):219-28.

115. Netherland J, Botsko M, Egan JE, Saxon AJ, Cunningham CO, Finkelstein R, et al. Factors affecting willingness to provide buprenorphine treatment. J Subst Abus Treat 2009;36(3):244-51.

116. Hutchinson E, Catlin M, Andrilla CH, Baldwin LM, Rosenblatt RA. Barriers to primary care physicians prescribing buprenorphine. Ann Fam Med 2014;12(2):128-33.

117. Arfken CL, Johanson CE, di Menza S, Schuster CR. Expanding treatment capacity for opioid dependence with office-based treatment with buprenorphine: national surveys of physicians. J Subst Abus Treat 2010;39(2):96-104.

118. Rosenblatt RA, Andrilla CH, Catlin M, Larson EH. Geographic and specialty distribution of US physicians trained to treat opioid use disorder. Ann Fam Med 2015;13(1):23-6.

119. Stein BD, Gordon AJ, Dick AW, Burns RM, Pacula RL, Farmer $\mathrm{CM}$, et al. Supply of buprenorphine waivered physicians: the influence of state policies. J Subst Abus Treat 2015;48(1):104-11.

120. Stein BD, Pacula RL, Gordon AJ, Burns RM, Leslie DL, Sorbero $\mathrm{MJ}$, et al. Where is buprenorphine dispensed to treat opioid use disorders? The role of private offices, opioid treatment programs, and substance abuse treatment facilities in urban and rural counties. Milbank Q 2015;93(3):561-83.

121. Stein BD, Sorbero M, Dick AW, Pacula RL, Burns RM, Gordon AJ. Physician capacity to treat opioid use disorder with buprenorphine-assisted treatment. JAMA. 2016;316(11):1211-2.

122. Dick AW, Pacula RL, Gordon AJ, Sorbero M, Burns RM, Leslie $\mathrm{D}$, et al. Growth in buprenorphine waivers for physicians increased potential access to opioid agonist treatment, 2002-11. Health Aff (Millwood) 2015;34(6):1028-34.

123. Wen H, Hockenberry JM, Borders TF, Druss BG. Impact of Medicaid expansion on Medicaid-covered utilization of buprenorphine for opioid use disorder treatment. Med Care 2017;55(4):336-41.

124. Jones CM, Campopiano M, Baldwin G, McCance-Katz E. National and state treatment need and capacity for opioid agonist medicationassisted treatment. Am J Public Health 2015;105(8):e55-e63.

125. Jones CM, McCance-Katz EF. Characteristics and prescribing practices of clinicians recently waivered to prescribe buprenorphine for the treatment of opioid use disorder. Addiction. 2019;114(3):471-82.

126. Thomas CP, Doyle E, Kreiner PW, Jones CM, Dubenitz J, Horan A, et al. Prescribing patterns of buprenorphine waivered physicians. Drug Alcohol Depend 2017;181:213-8.

127. Andrilla CHA, Moore TE, Patterson DG, Larson EH. Geographic distribution of providers with a DEA waiver to prescribe buprenorphine for the treatment of opioid use disorder: a 5-year update. J Rural Health 2019;35(1):108-12.

128. Duncan LG, Mendoza S, Hansen H. Buprenorphine maintenance for opioid dependence in public sector healthcare: benefits and barriers. J Addict Med Ther Sci 2015;1(2):31-6.

129. Medicine ACoAA. Fellowship training opportunities 2019 [Available from: https://www.acaam.org/applicationsaccreditation-now-accepted/.

130. Mark TL, Kranzler HR, Poole VH, Hagen CA, McLeod C, Crosse $\mathrm{S}$. Barriers to the use of medications to treat alcoholism. Am J Addict 2003;12(4):281-94.

131. Knudsen HK, Oser CB, Abraham AJ, Roman PM. Physicians in the substance abuse treatment workforce: understanding their employment within publicly funded treatment organizations. J Subst Abus Treat 2012;43(2):152-60.

132. Hagedorn HJ, Wisdom JP, Gerould H, Pinsker E, Brown R, Dawes M, et al. Implementing alcohol use disorder pharmacotherapy in primary care settings: a qualitative analysis of provideridentified barriers and impact on implementation outcomes. Addict Sci Clin Pract 2019;14(1):24.

133. Bride BE, Abraham AJ, Kintzle S, Roman PM. Social workers' knowledge and perceptions of effectiveness and acceptability of medication assisted treatment of substance use disorders. Soc Work Health Care 2013;52(1):43-58.

134. Fiscella K, Wakeman SE, Beletsky L. Buprenorphine deregulation and mainstreaming treatment for opioid use disorder: $\mathrm{X}$ the $\mathrm{X}$ waiver. JAMA Psychiatry 2018.

135. Compton WM, Jones CM, Stein JB, Wargo EM. Promising roles for pharmacists in addressing the U.S. opioid crisis. Res Soc Adm Pharm. 2017 15(8):910-916 
136. Lombardi BM, Zerden LS, Guan T, Prentice A. The role of social work in the opioid epidemic: office-based opioid treatment programs. Soc Work Health Care 2019;58(3):339-44.

137. Andrews CM, Darnell JS, McBride TD, Gehlert S. Social work and implementation of the Affordable Care Act. Health Soc Work 2013;38(2):67-71.

138. Association of American Medical Colleges. Physician supply and demand through 2025: key findings. 2015.

139. Oliva EM, Harris AH, Trafton JA, Gordon AJ. Receipt of opioid agonist treatment in the Veterans Health Administration: facility and patient factors. Drug Alcohol Depend 2012;122(3):241-6.

140. Abraham AJ, Rieckmann T, McNulty T, Kovas AE, Roman PM. Counselor attitudes toward the use of naltrexone in substance abuse treatment: a multi-level modeling approach. Addict Behav 2011;36(6):576-83.

141. Abraham AJ, Ducharme LJ, Roman PM. Counselor attitudes toward pharmacotherapies for alcohol dependence. J Stud Alcohol Drugs 2009;70(4):628-35.

142. Rieckmann TR, Kovas AE, McFarland BH, Abraham AJ. A multi-level analysis of counselor attitudes toward the use of buprenorphine in substance abuse treatment. J Subst Abus Treat 2011;41(4):374-85.

143. Molfenter T, Sherbeck C, Zehner M, Quanbeck A, McCarty D, Kim JS, et al. Implementing buprenorphine in addiction treatment: payer and provider perspectives in Ohio. Subst Abuse Treat Prev Policy 2015;10:13.

144. Thomas SE, Miller PM. Knowledge and attitudes about pharmacotherapy for alcoholism: a survey of counselors and administrators in community-based addiction treatment centres. Alcohol Alcohol 2007;42(2):113-8.

145. Facing Addiction in America: the Surgeon General's Report on Alcohol, Drugs, and Health. Reports of the Surgeon General. Washington (DC) 2016.

146. Volkow ND, Jones EB, Einstein EB, Wargo EM. Prevention and treatment of opioid misuse and addiction: a review. JAMA Psychiatry 2019;76(2):208-16.

147. Abraham AJ, Andrews CM, Yingling ME, Shannon J. Geographic disparities in availability of opioid use disorder treatment for Medicaid enrollees. Health Serv Res 2018;53(1):389-404.

148. Abraham AJ, Adams GB, Bradford AC, Bradford WD. Countylevel access to opioid use disorder medications in medicare Part D (2010-2015). Health Serv Res 2019;54(2):390-8.

149. Compton WM, Gfroerer J, Conway KP, Finger MS. Unemployment and substance outcomes in the United States 2002-2010. Drug Alcohol Depend 2014;142:350-3.

150. The Henry J. Kaiser Family Foundation. Many people with substance abuse problems may find few to treat them2015 May 1, 2015. Available from: http://khn.org/news/the-many-people-withsubstance-abuse-problems-may-find-few-to-treat-them/.

151. Ober AJ, Watkins KE, Hunter SB, Ewing B, Lamp K, Lind M, et al. Assessing and improving organizational readiness to implement substance use disorder treatment in primary care: findings from the SUMMIT study. BMC Fam Pract 2017;18(1):107.

152. Watkins KE, Ober AJ, Lamp K, Lind M, Setodji C, Osilla KC, et al. Collaborative care for opioid and alcohol use disorders in primary care: the SUMMIT Randomized Clinical Trial. JAMA Intern Med 2017;177(10):1480-8

153. Ober AJ, Watkins KE, Hunter SB, Lamp K, Lind M, Setodji CM. An organizational readiness intervention and randomized controlled trial to test strategies for implementing substance use disorder treatment into primary care: SUMMIT study protocol. Implement Sci 2015;10:66.

154. LaBelle CT, Han SC, Bergeron A, Samet JH. Office-Based Opioid Treatment with Buprenorphine (OBOT-B): Statewide
Implementation of the Massachusetts Collaborative Care Model in Community Health Centers. J Subst Abus Treat 2016;60:6-13.

155. Brooklyn JR, Sigmon SC. Vermont hub-and-spoke model of care for opioid Use disorder: development, implementation, and impact. J Addict Med 2017;11(4):286-92.

156. Rawson R, Cousins SJ, McCann M, Pearce R, Van Donsel A. Assessment of medication for opioid use disorder as delivered within the Vermont hub and spoke system. J Subst Abus Treat 2019;97:84-90.

157. Miele GM, Caton L, Freese TE, McGovern M, Darfler K, Antonini VP, et al. Implementation of the hub and spoke model for opioid use disorders in California: rationale, design and anticipated impact. J Subst Abus Treat 2019.

158. Reif S, Brolin MF, Stewart MT, Fuchs TJ, Speaker E, Mazel SB. The Washington State Hub and Spoke Model to increase access to medication treatment for opioid use disorders. J Subst Abuse Treat. 2019.

159. Frank JW, Wakeman SE, Gordon AJ. No end to the crisis without an end to the waiver. Subst Abus 2018;39(3):263-5.

160. Wakeman SE, Barnett ML. Primary care and the opioid-overdose crisis-buprenorphine myths and realities. N Engl J Med 2018;379(1):1-4.

161. Spetz J, Toretsky C, Chapman S, Phoenix B, Tierney M. Nurse practitioner and physician assistant waivers to prescribe buprenorphine and state scope of practice restrictions. JAMA. 2019;321(14):1407-8

162. Andrilla CHA, Patterson DG, Moore TE, Coulthard C, Larson EH. Projected contributions of nurse practitioners and physicians assistants to buprenorphine treatment services for opioid use disorder in rural areas. Med Care Res Rev. 2018: 1077558718793070.

163. Andrews CM, Grogan CM, Smith BT, Abraham AJ, Pollack HA, Humphreys $\mathrm{K}$, et al. Medicaid benefits for addiction treatment expanded after implementation of the Affordable Care Act. Health Aff (Millwood) 2018;37(8):1216-22.

164. Reif S, Creedon TB, Horgan CM, Stewart MT, Garnick DW. Commercial health plan coverage of selected treatments for opioid use disorders from 2003 to 2014. J Psychoactive Drugs 2017;49(2):102-10.

165. Here's what it would cost to fix the opioid crisis, according to 5 experts: money; 2017 [Available from: http://money.com/money/ 5032445/cost-fix-opioid-crisis/.

166. Leggio L, Falk DE, Ryan ML, Fertig J, Litten RZ. Medication development for alcohol use disorder: a focus on clinical studies. Handb Exp Pharmacol. 2019.

167. Litten RZ, Egli M, Heilig M, Cui C, Fertig JB, Ryan ML, et al. Medications development to treat alcohol dependence: a vision for the next decade. Addict Biol 2012;17(3):513-27.

168. Ray LA, Bujarski S, Roche DJO, Magill M. Overcoming the "Valley of Death" in medications development for alcohol use disorder. Alcohol Clin Exp Res 2018;42(9):1612-22.

169. Witkiewitz K, Litten RZ, Leggio L. Advances in the science and treatment of alcohol use disorder. Sci Adv. 2019;5(9):eaax4043.

170. Lofwall MR, Walsh SL, Nunes EV, Bailey GL, Sigmon SC, Kampman KM, et al. Weekly and monthly subcutaneous buprenorphine depot formulations vs daily sublingual buprenorphine with naloxone for treatment of opioid use disorder: a randomized clinical trial. JAMA Intern Med 2018;178(6):764-73.

171. Volkow ND, Collins FS. The role of science in addressing the opioid crisis. N Engl J Med 2017;377(4):391-4.

172. Rasmussen K, White DA, Acri JB. NIDA's medication development priorities in response to the opioid crisis: ten most wanted. Neuropsychopharmacology. 2019;44(4):657-9.

Publisher's Note Springer Nature remains neutral with regard to jurisdictional claims in published maps and institutional affiliations. 